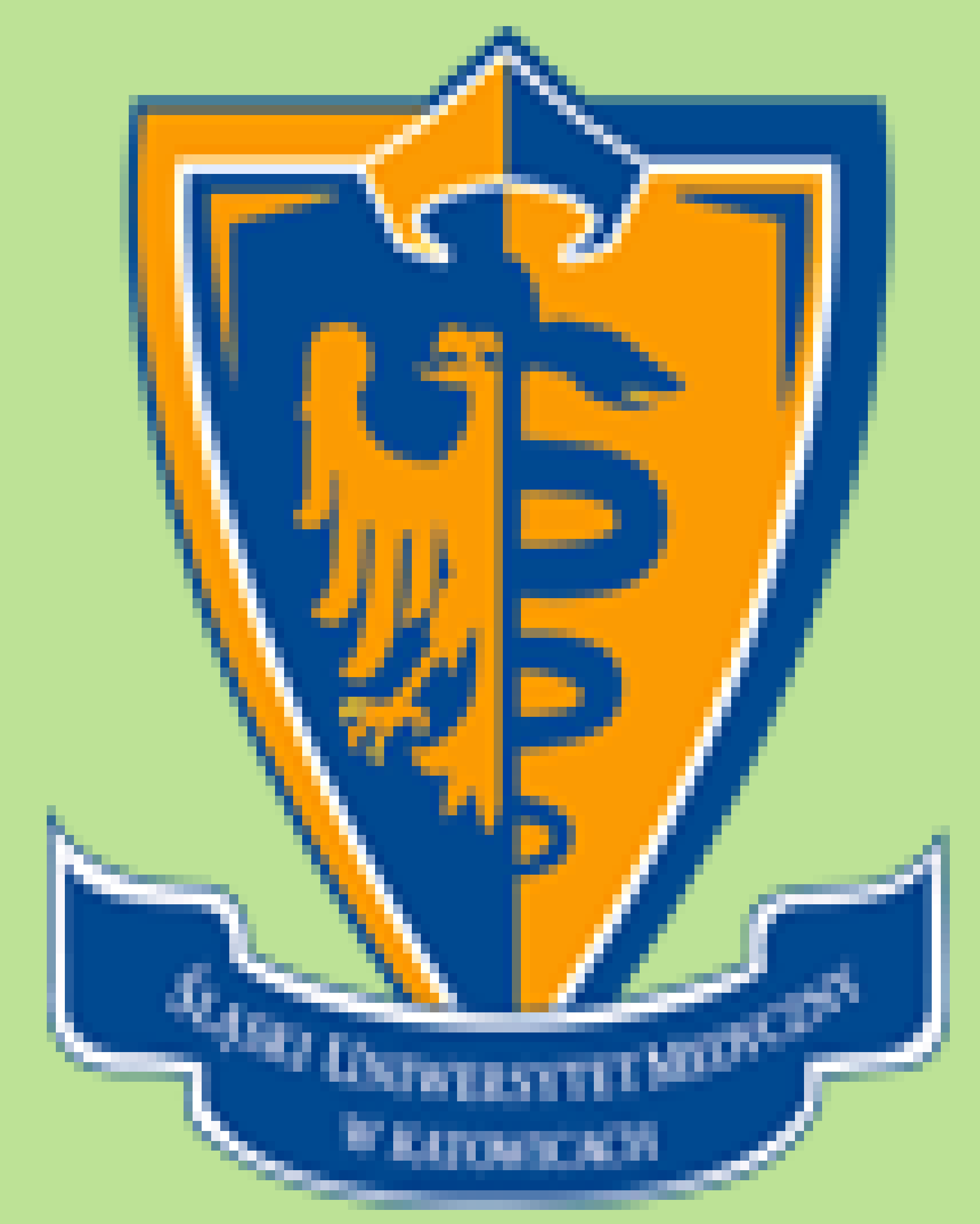

\title{
THE INFLUENCE OF THE BODY FAT DISTRIBUTION ON THE SELECTED BIOCHEMICAL PARAMETERS IN A GROUP OF WOMEN WITH POLYCYSTIC OVARY SYNDROME - PRELIMINARY REPORT
}

\section{Anna Brończyk-Puzoń ${ }^{1}$, Justyna Nowak ${ }^{1}$, Karolina Kulik-Kupka ${ }^{1}$, Aneta Koszowska ${ }^{1}$, Barbara Zubelewicz-Szkodzińska ${ }^{1}$ \\ 1. Department of Nutrition Related Prevention, School of Public Health in Bytom, Medical University of Silesia.}

\section{INTRODUCTION:}

Polycystic Ovary Syndrome is usually accompanied by metabolic changes such as carbohydrate and lipid metabolism disorders and obesity.

AIM:

The aim of the study is to determine the impact of the deployment of body fat on selected biochemical parameters in women with Polycystic Ovarian Syndrome.

\section{MATERIALS AND METHODS:}

The study included a group of 45 women with diagosed Polycystic Ovarian Syndrome based on the 2003 Rotterdam criteria. In order to evaluate the distribution of body fat, the WHR (Waist-Hip Ratio) index was used. For the diagnosis of abdominal obesity we adopted the values $\geq 0.85$ and $<0.85$ for gluteal-femoral obesity.

\section{RESULTS:}

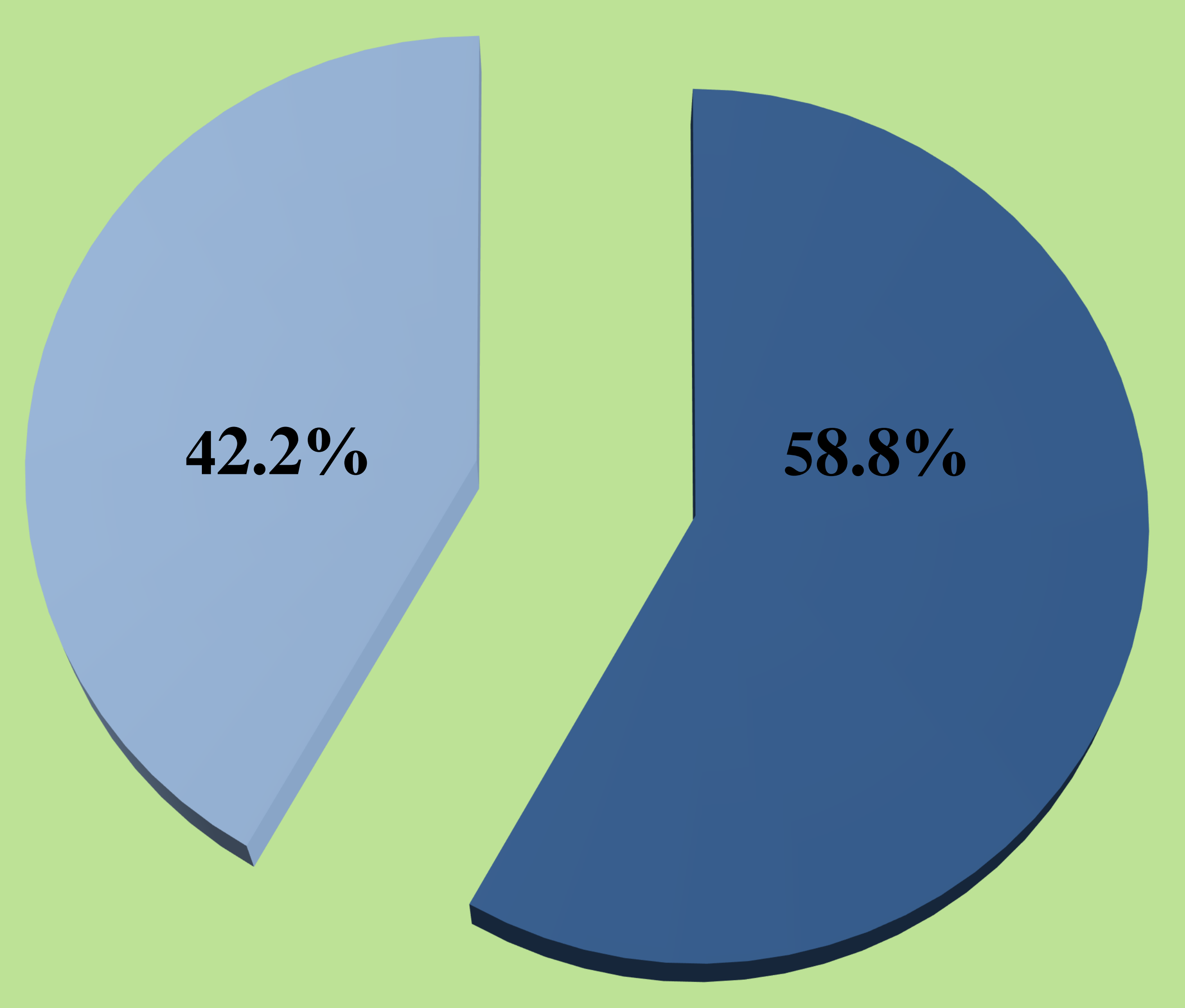

- Women with gluteal-femoral obesity

Women with abdominal obesity

\begin{tabular}{|c|c|c|c|}
\hline WHR & $\begin{array}{c}\text { Women with gluteal-femoral } \\
\text { obesity }\end{array}$ & $\begin{array}{c}\text { Women with abdominal } \\
\text { obesity }\end{array}$ & P-value \\
\hline $\begin{array}{c}\text { HDL cholesterol } \\
(\mathrm{mg} / \mathrm{dl})\end{array}$ & $71.08 \pm 14.84$ & $48.95 \pm 8.48$ & $<0.0001$ \\
\hline TG (mg/dl) & $81.80 \pm 34.65$ & $125.58 \pm 63.23$ & 0.0054 \\
\hline HOMA index & $1.97 \pm 1.64$ & $3.07 \pm 1.18$ & 0.0186 \\
\hline SHGB (nmol/l) & $25.69 \pm 31.53$ & $32.44 \pm 19.01$ & 0.0008 \\
\hline $\begin{array}{c}\text { Free testosterone } \\
\text { (pg/ml) }\end{array}$ & $5.74 \pm 4.19$ & $11.81 \pm 6.37$ & 0.0004 \\
\hline FAI index & $4.02 \pm 3.31$ & $8.16 \pm 4.00$ & 0.0017 \\
\hline
\end{tabular}

The group of women aged 18-40 years $(16.4 \pm 5.6)$ entered the study. Significant differences were found between the group of women with gluteal-femoral obesity and the group of women with abdominal obesity in terms of average values of: HDL cholesterol $(\mathrm{mg} / \mathrm{dl})$ $(71.08 \pm 14.84$ vs. $48.95 \pm 8.48 ; \mathrm{p}<0.0001)$, TG $(\mathrm{mg} / \mathrm{dl})(81.80 \pm 34.65$ vs. $125.58 \pm 63.23$; $\mathrm{p}=0.0054)$, HOMA index $(1.97 \pm 1.64$ vs. $3.07 \pm 1.18 ; \mathrm{p}=0.0186), \quad$ SHGB $(\mathrm{nmol} / \mathrm{l})$ $(25.69 \pm 31.53$ vs. $32.44 \pm 19.01 ; \mathrm{p}=0.0008)$, free testosterone $(\mathrm{pg} / \mathrm{ml})(5.74 \pm 4.19$ vs. 11.81 \pm 6.37 ; $=0.0004)$, and FAI index (4.02 \pm 3.31 vs. $8.16 \pm 4.00 ; \mathrm{p}=0.0017)$.

\section{CONCLUSION}

Evaluation of body fat distribution seems to be useful in determining the risk of carbohydrate metabolism and lipid metabolism disorders as well as hyperandrogenemia in with Polycystic Ovarian Syndrome patients. 